\title{
Izboljšanje zaznave sovražnega in zlonamernega govora s pomočjo slovarja besed
}

\author{
Sašo Kolac \\ Fakulteta za elektrotehniko, \\ računalništvo in informatiko \\ Inštitut za računalništvo \\ Koroška cesta 46, \\ 2000 Maribor, Slovenija \\ saso.kolac@student.um.si
}

\author{
Aljaž Soderžnik \\ Fakulteta za elektrotehniko, \\ računalništvo in informatiko \\ Inštitut za računalništvo \\ Koroška cesta 46 , \\ 2000 Maribor, Slovenija \\ aljaz.soderznik@student.um.si \\ Borko Bošković \\ Fakulteta za elektrotehniko, \\ računalništvo in informatiko \\ Inštitut za računalništvo \\ Koroška cesta 46 , \\ 2000 Maribor, Slovenija \\ borko.boskovic@um.si
}

\author{
Simon Slemenšek \\ Fakulteta za elektrotehniko, \\ računalništvo in informatiko \\ Inštitut za računalništvo \\ Koroška cesta 46 , \\ 2000 Maribor, Slovenija \\ simon.slemensek1@student.um.si
}

\section{POVZETEK}

V članku je predstavljena metoda, ki temelji na optimizaciji predprocesiranja besedil z namenom izboljšati natančnost klasifikacije sovražnega govora z uporabo algoritmov strojnega učenja. Žaljive kratice in zaznamke nadomestimo $\mathrm{z}$ žetonom <curseword >, s čimer algoritmi lažje klasificirajo sovražni in zlonamerni govor. V članku so primerjani rezultati klasifikacij z in brez naše metode algoritmov naivni bayes, logistične regresije, podporni vektorji, naključni gozdovi, gradiento pospeševanje regresijskih gozdov, nevronske mreže in "Bagging"klasifikator. Testna besedila smo dobili iz socialnega omrežja Twitter.

\section{Kjučne besede}

jezikovne tehnologije, klasifikacija, sovražni govor, strojno učenje, zlonamerni govor

\section{UVOD}

Svoboda izražanja je temeljna človekova pravica in predpogoj za obstoj demokratične družbe. Kot vse pravice, tudi svobode izražanja ni dopustno izrabljati na škodo drugih in je zamejena s človekovim dostojanstvom in $\mathrm{z}$ načelom varovanja javnega reda in miru. Nekatere oblike izražanja so zato zakonsko prepovedane ali veljajo za družbeno nesprejemljive, na primer grožnje, žalitve, komunikacija z namenom preslepitve in sovražni govor.

Sovražni in zlonamerni govor se navezujeta na besedila, ki so do posameznikov ali skupine ljudi žaljiva, prestrašujoča, poniževalna ali takšna, da spodbujajo nasilje [9]. Njegov cilj je razčlovečiti tiste, proti katerim je namenjen. Prepoznavanje takšnih besedil na spletu je dandanes zelo pomembno, saj imajo socialni mediji $[6,8]$ zelo velik vpliv na človeško psiho.

Družbena omrežja in razne platforme za objavljanje spletnih videoposnetkov v svojih pravilih prepovedujejo širjenje sovraštva proti družbenim skupinam, posameznicam in posameznikom. Prepovedujejo tudi grožnje in nadlegovanje ter omejujejo objavljanje vsebin, ki niso primerne za mladoletne. Facebook, Twitter, YouTube, Microsoft, Google+, Instagram in Snapchat so se s podpisom posebnega kodeksa zavezali, da bodo večino upravičenih prijav nezakonitega sovražnega govora pregledali v roku 24 ur in onemogočili dostop do teh vsebin ob upoštevanju lokalne in evropske zakonodaje.

Problem na katerega naletimo je preveliko število besedil oz. objav, da bi lahko ljudje ročno preverjali, če se besedilo dejansko uvršča pod sovražni govor. Eden izmed načinov za soočanje s tem problemom so algoritmi strojnega učenja $[1,7,10]$, ki omogočajo dokaj uspešno zaznavo sovražnega govora.

V tem delu smo se osredotočili na predprocesiranje besedila $\mathrm{v}$ tvitih, tako da smo s pomočjo slovarja žaljivih besed zamenjali vse žaljive besede, ki so se pojavile $\mathrm{v}$ besedilih tvitoh $\mathrm{z}$ žetonom <curseword $>$. Nad predprocesiranim besedilom smo nato uporabili algoritme različnih vej strojnega učenja $\mathrm{v}$ programskem jeziku Python in medsebojno primerjali rezultate $\mathrm{z}$ in brez modifikacije pri predprocesiranju. Podatkovno bazo s približno 100.000 tviti smo pridobili iz repozitorija [3].

V pričujočem poglavju bomo predstavili ugotovitve sorodnih del. Sledi poglavje, ki opisuje predstavljeno metodo, ter potek eksperimenta $\mathrm{z}$ analizo rezultatov. Temu poglavju sledi poglavje, ki govori o naši razlagi rezultatov. Nazadnje sledi še zaključek, ki povzema ključne ugotovitve našega dela. 


\section{SORODNA DELA}

Podobno delo so opravili $\mathrm{v}$ [5], kjer so avtorji preizkusili pet modelov tradicionalnega strojnega učenja in nekaj modelov temelječih na nevronskih mrežah. Uporabili so naslednje modele:

1. Tradicionalni modeli strojnega učenja:

- Naivni Bayes (NB): z aditivno konstanto glajenja 1 ,

- Logistična regresija (LR): Linearna z L2 regularizacijsko konstanto 1 in z BFGS optimizacijo za omejen spomin,

- Metoda podpirnih vektorjev (SVM): Linearna z L2 regularizacijsko konstanto 1 in s funkcijo logistične izgube,

- Metoda naključnih gozdov (RF): Porazdelitev verjetnosti napovedi 10 naključnih dreves odločanja,

- Metoda gradientnega pospeševanja regresijskih gozdov (GBT): S konstanto učenja 1 in $\mathrm{s}$ funkcijo logistične izgube.

2. Modeli temelječi na nevronskih mrežah:

- Konvolucijska nevronska mreža (CNN): Modeli uporabljajo križno entropijo s softmax, kot funkcijo izgube in Adam kot optimizator,

- Ponavljajoče se dvosmerna nevronska mreža (RNN): Modeli uporabljajo križno entropijo s sigmoid, kot funkcijo izgube in Adam kot optimizator. Uporabljen je tudi vratni mehanizem GRU,

- Variacije zgornjih dveh modelov.

Modele so preizkusili na sovražnih in zlonamernih besedilih iz socialnega omrežja Twitter. Predstavili so možnost izboljšave klasifikatorjev z uporabo dodatnih lastnosti in kontekstnih podatkov. Iz eksperimentov so ugotovili, da je najbolj natančen model temelječ na dvosmerni nevronski mreži z GRU, naučen na besednih lastnostih z metodo modulov za grozdenje latentnih tem. Izmerjena vrednost mere F1 za model je bila $80.5 \%$.

Članek [2] opisuje metodo za zaznavanje neprimernega obnašanja uporabnikov na Twitterju. Predstavili so tudi robustno metodologijo za ekstrakcijo besedil, uporabniških in omrežno temelječih atributov, preučevanja lastnostni agresivnih in ustrahujočih uporabnikov ter kakšne lastnosti jih ločijo od navadnih uporabnikov. Ugotovili so, da uporabniki, ki ustrahujejo, manj objavljajo na splet, so deležni manj socialnih skupin in so manj popularni od navadnih uporabnikov. Agresivni ljudje so relativno popularni in imajo več negativnosti v svojih objavah. Dokazali so, da lahko algoritmi strojnega učenja zaznajo agresivno in ustrahojoče vedenje uporabnikov z več kot 90 \% AUC (angl. Area Under the Curve).

Delo [4] opisuje dvokoračno metodo klasifikacije zlonamernega jezika na twitterju in nato nadaljno delenje teh klasifikacij v specifične tipe. To metodo primerjajo z enokoračno, ki opravi samo eno več razredno klasifikacijo v delenje tipov za zaznavanje rasističnih in seksističnih besedil. Za enokoračno metodo so ugotovili, da je najboljša rešitev nevronska mreža HybridCNN z vrednostjo mere F1 82.7 \%, za dvokoračno pa tradicionalni model logistične regresije $\mathrm{z}$ vrednostjo mere F1 $82.4 \%$.

Članek [7] opisuje klasifikacijo besedil na twitterju v kategorije seksistično, rasistično ali nič od tega. Preizkusili so veliko različnih arhitektur globokega učenja in z eksperimenti pokazali, da so metode temelječe na semantični analizi besed boljše od metod temelječih na znakovnih in besednih n-gramih za približno $18 \%$ vrednosti mere F1.

Članek [1] opisuje metodo za avtomatizirano zaznavo sovražnega govora na twitterju z ekstrakcijo lastnosti besedil na različnih konceptualnih nivojih in apliciranjem več razredne klasifikacije nad njimi. Sistem izkorišča variacije statističnih modelov in vzorce temelječe na pravilih. Obstaja tudi pomožni repozitorij z uteženimi vzorcei, ki izboljšajo natančnost tako, da povežejo besedilo z njegovim ocenjenim vnosom.

\section{PREDSTAVITEV METODE IN EKSPERI- MENTA}

\subsection{Metoda}

Predstavljena metoda temelji na optimizaciji predprocesiranja besedil z namenom izboljšati natančnost klasifikacije sovražnega govora $\mathrm{z}$ uporabo algoritmov strojnega učenja.

Ključna razlika med predstavljeno metodo in metodami drugih avtorjev se skriva v koraku predprocesiranja. Pri predstavljeni metodi $\mathrm{v}$ tem koraku poleg vseh ostalih tipičnih elementov predprocesiranja, vse besede iz vsebine sporočila, ki so v slovarju žaljivih besed, zamenjamo z žetonom <curseword $>$, s čimer algoritmi lažje klasificirajo sovražni in zlonamerni govor.

Delovanje predstavljene metode je podrobno opisano v naslednjem podpoglavju, ko opisujemo izvedbo eksperimenta.

\subsection{Eksperiment}

Za implementacijo smo uporabili programski jezik Python. Ene izmed pomembnejših knjižnic, ki smo jih uporabili $\mathrm{v}$ implementaciji so Numpy, katera nudi hitre in učinkovite operacije na poljih. Programski jezik razširi v visoko nivojni jezik za manipulacijo numeričnih podatkov podobno jeziku Matlab. Sklearn smo uporabili za orodja, ki jih nudi za rudarjenje in analizo podatkov. Uporabili smo še knjižnico Pandas, ki nudi dobre podatkovne strukture in orodja za analizo podatkov in NLTK, ki je knjižnica za podporo programom, ki se ukvarjajo z naravnim jezikom ter Tweepy, ki poenostavi dostop do API-jev socialnega omrežja Twitter.

\subsubsection{Pridobivanje korpusa}

Za pridobivanje podatkov smo najprej morali na socialnem omrežju Twitter zaprositi za spletni račun razvijalca. S tem smo pridobili dostop do Twitterjeve spletne storitve v katero smo pošiljali IDje tvitov iz repozitorija [3], storitev pa nam je vrnila vsebino tvita. Zaradi omejitve števila klicov spletne storitve je pridobivanje vseh tvitov iz repozitorija trajalo približno 72 ur. Od 99799 tvitov, katere smo pridobili iz repozitorija [3] smo jih s pomočjo spletne storitve Tiwtter uspešno prenesli 79768, saj so Twitterjevi moderatorji nekaj 
žaljivih in zlonamernih tvitov od takrat, ko je bila baza $\mathrm{z}$ IDji tvitov objavljena že uspešno odstranili. Izvajanje učnih algoritmov je implementirano v programskem jeziku Python po zgledu članka [5].

\subsubsection{Predprocesiranje}

Gre za klasično predprocesiranje besedila, kot je odstranitev posebnih znakov, "hash tags", spletne povezav in podobnih elementov z uporabo regularnih izrazov. Podatke razdelimo na 10 naključnih prečnih preverjanj (ang. folds). Z našo metodo, še v objavah iz Twitterja zamenjamo žaljive besede $\mathrm{z}$ žetonom <curseword > za nadaljno boljše učenje algoritmov. Kot žaljive besede smo smatrali vse besede, ki so se pojavile na seznamu Googlovih prepovedanih besed (vir: https://www.freewebheaders.com/full-list-of-badwords-banned-by-google/).

\subsubsection{Implementiranje dodatnih učnih algoritmov}

Zraven naštetim učnim algoritmom članka [5] v poglavju 2 smo še implementirali nevronsko mrežo MLP in tradicionalni model "Bagging"klasifikator. Nevronsko mrežo smo izbrali zaradi dobrih rezultatov v sorodnih člankih. Za izbran tradicionalni model pa je znano, da dobro deluje kadar nimajo besede zelo podobnih pomenov.

\subsubsection{Učenje in evaluacija algoritmov}

Po predprocesiranju smo algoritme učili 2 krat. Enkrat z našo metodo optimizacije in enkrat brez. Po končanem učenjo smo še naredili evulacijo pridobljenih učnih modelov. Največjo pomembnost smo namenili meri F1 - enačba (1), ki predstavlja harmonično povprečje med senzitivnstjo in preciznostjo. Najboljšo vrednost doseže pri 1 (popolna preciznost in senzitivnost), najslabšo pa pri številu 0 .

$$
F_{1}=2 \cdot \frac{\text { preciznost } \cdot \text { senzitivnost }}{\text { preciznost }+ \text { senzitivnost }}
$$

\subsection{Analiza rezultatov}

Pri vsaki metodi smo naredili deset poskusov z naključno izbranimi podatki. Uporabljali smo mero F1, preciznost, senzitivnost, mikro, makro ter uteženo povprečje. Primerjava rezultatov je narejena glede na povprečje vseh poskusov $\mathrm{z}$ uporabo mere $\mathrm{F} 1$, kot je razvidno na slikah 1 in 2 .

Slika 1 prikazuje mero F1 posameznih metod brez in z našo modifikacijo pri predprocesiranju besedila $v$ tvitih. Pri sovražnem govoru nam je uspelo metodo SVM v povprečju izboljšati za $7 \%$, medtem ko so metode NB, LR, RF in MLP ostale primerljivo dobre. Občutno poslabšali pa sta se metodi GBT in BC (za $9 \%$ oziroma $8 \%$ ).

Kot je razvidno iz slike 2 nam pri zaznavanju zlonamernega govora z modifikacijo pri predprocesiranju ni uspelo doseči boljše mere F1 pri nobeni metodi . Najslabše rezultate smo dosegli pri metodah GBT in BC (7\% oziroma $5 \%$ poslabšanje s predprocesiranjem). Zakaj menimo, da je temu tako, smo opisali v naslednjem poglavju.

Pri zaznavi sovražnega govora sta nam metodi, ki smo ju dodatno implementirali (MLP in BC) prinesli najslabše rezultate mere F1 (37 \% in $42 \%$ ) od vseh sedmih preizkušenih

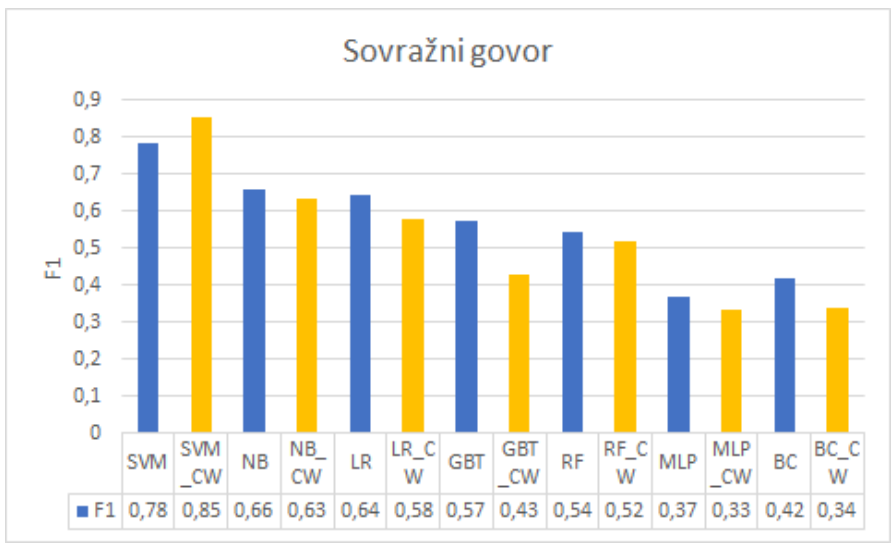

Slika 1: Primerjava uspešnosti metod za zaznavo sovraznega govora

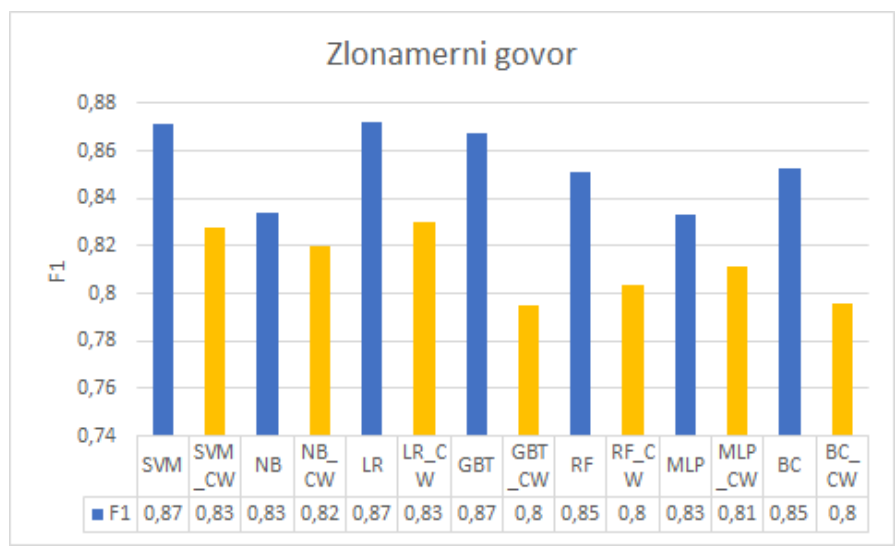

Slika 2: Primerjava uspešnosti metod za zaznavo zlonamernega govora

metod. Z modificiranim predprocesiranjem se je mera F1 še dodatno poslabšala na $33 \%$ (MLP) in $34 \%$ (BC).

Pri zaznavi zlonamernega govora sta se metodi MLP in BC odrezali malce bolje, še vedno pa nista bili med najnatančnejšimi. Brez uporabe slovarja pri predprocesiranju si je metoda BC delila četrto mesto z metodo RF, obe sta imeli mero F1 $85 \%$. Medtem, ko si je metoda MLP delila zadnje mesto z metodo NB z mero F1 $83 \%$. Ko smo vključili še predprocesiranje s slovarjem je metoda BC skupaj z metodama GBT in RF celo kazala najslabšo mero F1 izmed vseh metod $80 \%$, metoda MLP pa je bila le mesto nad njimi z mero F1 $81 \%$.

Pri vseh metodah smo uporabili optimalne parametre, kateri so bili izračunani s pomožno funkcijo. Tako smo dobili za SVM parameter Alpha vrednost 0.0001, izguba je bila logaritmična s kaznijo 12, L1 razmerje 0.15 , ter moč $\mathrm{T}$ parametra 0.5. Pri metodi NB smo dobili parameter Alpha z vrednostjo 1 in omogočili učenje z zgodovino. Pri LR metodi smo uporabili logaritem Lbgfs s kaznijo 12 ter omejili iteracije na 100. Za GBT metodo smo omejili globino na 1 in uporabili število približkov na 100 ter stopnjo učenja 0.1. Metoda RF je bila najmanj omejena, saj nismo omejevali globine in širine, uporabili pa smo kriterijsko metodo 
Gini. Pri metodi MLP smo uporabili skrite nivoje velikosti 100, parameter Alpha z vrednostjo 0.0001, število iteracij smo omejili na 200 in uporabljali algoritem Adam. Za BC metodo smo uporabili 5 približkov z neomejenim številom opravil, vsi približki so imeli tudi namestnike po funkciji Bootstrap.

\section{DISKUSIJA}

S pomočjo predlaganega predprocesiranja smo poenotili žaljive besede. To pa je algoritmu SVM omogočilo, da je dosegel boljše rezultate. Razlog temu bi lahko bil ta, da so se vse žaljive besede preslikale v isti vektor. To pa je algoritmu omogočilo lažje določanje hiperravnin zaradi manjšega šuma v podatkih.

Pri predprocesiranju smo v slovarju imeli tako zlonamerne, kot tudi sovražne besede. Ko smo te besede zamenjali z enakim žetonom, smo posplošili klasifikacijo in zmanjšali razlike med vrstami besedil.

$\mathrm{V}$ prihodnosti bi lahko predprocesiranje izboljšali z večjim in boljšim slovarjem. Lahko bi ločili besede slovarja za vsak razred klasifikacije. Lahko bi v slovar vključili besedne zveze in fraze.

Natančnost klasifikacij, bi lahko izboljšali z bolj podrobnim deljenjem žaljivih besed na več različnih žetonov (v tem poskusu je samo 1 tip žetona). Nadalje bi jo izboljšali z razširjanjem slovarja žaljivih besed.

Lahko bi uporabili različni korpus za zlonamerni in sovražni govor. S tem bi dosegli bolj robustno in podrobno zaznavo žaljivega govora. Po primerjanju rezultatov, bi še lahko poskusili zgraditi nove hibridne in amsambelske metode učenja iz najboljših testiranih algoritmov.

\section{ZAKLJUČEK}

Na spletu je veliko različnih primerkov sovražnega in zlonamernega govora. Pri prepoznavi je eden izmed problemov možne variacije žaljivih besed, ki imajo podoben pomen. Rezultati našega dela so pokazali, da lahko naredimo majhno izboljšavo klasifikacij sovražnega govora takih primerov pri algoritmu SVM, če zmanjšamo raznolikost žaljivih besed s slovarjem žaljvih besed, ki te besede zamenja z žetonom.

Uspešnost naših metod smo ocenili z mero F1. Strokovnjaki so dosegli z njihovo najboljšo izkazano metodo SVM pri sovražnem govoru mero $\mathrm{F} 1 \mathrm{z}$ vrednostjo 78 \%, z našo metodo slovarja žaljivih besed pa smo dosegli vrednost $85 \%$. Za zlonamerni govor so $\mathrm{s}$ to metodo dosegli vrednost mere F1 87 $\%$, z našo metodo pa smo dosegli le $83 \%$. Pri ostalih rezultatih smo glede na mero F1 za sovražni in zlonamerni govor dosegli slabše rezultate pri metodah naivni bayes, linearna regresija, gradient boosting dreves in naključni gozd.

Prav tako je do razlik v rezultatih enakih testiranih učnih metod kot v članku [5], prišlo zaradi tega, ker nismo mogli pridobiti vseh tvitov iz baze, ker so upravljalci Twitterja med tem že izbrisali nekatere zlonamerne in sovražne tvite.

S pomočjo predlaganega predprocesiranja smo poenotili žaljive besede. To pa je algoritmu SVM omogočilo, da je dosegel boljše rezultate. Razog temu bi lahko bil to, da so se vse žaljive besede preslikale v enak vektor. To pa je algoritmu omogočilo lažje doloćanje hiperravnine, zaradi manjšega šuma v podatkih.

\section{Literatura}

[1] Sasha Uritsky Stan Matwin Amir H. Razavi, Diana Inkpen. Offensive language detection using multi-level classification. Canadian AI 2010: Advances in Artificial Intelligence, Berlin, Heidelberg, 2010.

[2] Jeremy Blackburn Emiliano De Cristofaro Gianluca Stringhini Athena Vakali Despoina Chatzakou, Nicolas Kourtellis. Mean birds: Detecting aggression and bullying on twitter. WebSci '17, Troy, NY, USA, 2017.

[3] Antigoni-Maria Founta, Constantinos Djouvas, Despoina Chatzakou, Ilias Leontiadis, Jeremy Blackburn, Gianluca Stringhini, Athena Vakali, Michael Sirivianos, and Nicolas Kourtellis. Large scale crowdsourcing and characterization of twitter abusive behavior. In 11th International Conference on Web and Social Media, ICWSM 2018. AAAI Press, 2018.

[4] Pascale Fung Ji Ho Park. One-step and twostep classification for abusive language detection on twitter. Proceedings of the First Workshop on Abusive Language Online, Vancouver, BC, Canada, 2017.

[5] Younghun Lee, Seunghyun Yoon, and Kyomin Jung. Comparative studies of detecting abusive language on twitter. Proceedings of the Second Workshop on Abusive Language Online (ALW2), Brussels, Belgium, 2018.

[6] Chikashi Nobata, Joel Tetreault, Achint Thomas, Yashar Mehdad, and Yi Chang. Abusive language detection in online user content. $W W W$ ' 16 Proceedings of the 25th International Conference on World Wide Web, Montréal, Québec, Canada, 2016.

[7] Manish Gupta Vasudeva Varma Pinkesh Badjatiya, Shashank Gupta. Deep learning for hate speech detection in tweets. $W W W$ '17 Companion Proceedings of the 26th International Conference on World Wide Web Companion, Perth, Australia, 2017.

[8] Sara Sood, Judd Antin, and Elizabeth Churchill. Profanity use in online communities. $C H I$ ' 12 Proceedings of the SIGCHI Conference on Human Factors in Computing Systems, Austin, Texas, USA, 2012.

[9] William Warner and Julia Hirschberg. Detecting hate speech on the world wide web. Proceedings of the Second Workshop on Language in Social Media, Montréal, Canada, 2012.

[10] Guang Xiang, Bin Fan, Ling Wang, Jason Hong, and Carolyn Rose. Detecting offensive tweets via topical feature discovery over a large scale twitter corpus. CIKM '12 Proceedings of the 21st ACM international conference on Information and knowledge management, Maui, Hawaii, USA, 2012. 